\title{
Association of Toll-like receptor 2 polymorphisms with gout
}

\author{
YAN CAI $^{1,2,3^{*}}$, YI-HUA PENG $^{4 *}$, ZHONG TANG $^{1,2}$, XIAO-LAN GUO $^{1,2,3}$, \\ YU-FENG QING ${ }^{3,5}$, SU-HUA LIANG ${ }^{6}$, HONG JIANG ${ }^{3}$, WANG-TAI DANG ${ }^{3,5}$,

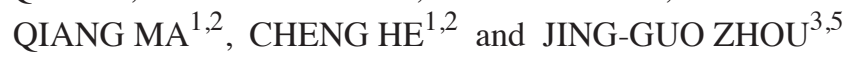 \\ ${ }^{1}$ Faculty of Laboratory Medicine, North Sichuan Medical College; ${ }^{2}$ Department of Clinical Laboratory, \\ ${ }^{3}$ Institute of Rheumatism Immunity and Departments of ${ }^{4}$ Endocrinology, ${ }^{5}$ Immunology and Rheumatology, \\ The Affiliated Hospital of North Sichuan Medical College; ${ }^{6}$ Department of Biology, North Sichuan Medical College, \\ Nanchong, Sichuan 637000, P.R. China
}

Received November 20, 2013; Accepted January 09, 2014

DOI: 10.3892/br.2014.224

\begin{abstract}
Gout is the most common autoinflammatory arthritis characterized by elevated serum urate and recurrent attacks of intra-articular crystal deposition of monosodium urate (MSU) in tissues. The pathogenesis of gout has not been fully determined, although certain genetic factors are involved in the development of gout. Accumulated data suggested that MSU crystal-induced inflammation is a paradigm of innate immunity. As Toll-like receptors (TLRs) are the underlying mechanisms of the innate immune response, the present study aimed to investigate whether $T L R 2$ polymorphisms are associated with gout. Two single-nucleotide polymorphisms (Arg677Trp and Arg753Gln, rs5743708) in TLR2 were genotyped by polymerase chain reaction-restriction fragment length polymorphism and the -196 to -174 del polymorphism was investigated using the allele-specific polymerase chain reaction in 431 individuals (215 patients with gout and 216 healthy controls). TLR2 Arg677Trp and Arg753Gln genotyping indicated that all the positive samples were of the wild-type genotype. No significant differences in genotype $\left(\chi^{2}=1.686\right.$, $\mathrm{P}=0.430)$ and allele $\left(\chi^{2}=1.430, \mathrm{P}=0.232\right)$ frequencies of the -196 to -174 del polymorphism between the patients with gout and the control groups was observed. Our results suggested that the TLR2 Arg677Trp, Arg753Gln and the -196 to -174 del
\end{abstract}

Correspondence to: Professor Jing-Guo Zhou, Department of Immunology and Rheumatology, The Affiliated Hospital of North Sichuan Medical College, 63 Wenhua Road, Nanchong, Sichuan 637000, P.R. China

E-mail: jgzhou@nsmc.edu.cn

Professor Su-Hua Liang, Department of Biology, North Sichuan Medical College, 63 Wenhua Road, Nanchong, Sichuan 637000, P.R. China

E-mail: liang830322@163.com

*Contributed equally

Key words: arthritis, Toll-like receptor 2, polymorphism, gout polymorphisms were not associated with susceptibility to primary gouty arthritis.

\section{Introduction}

Gout is an inflammatory and immune disease caused by monosodium urate (MSU) deposition in the synovial membrane of the joints, synovial cyst, cartilage and other tissues. Gout is characterized as acute or chronic arthritis, gouty stone, joint deformity, chronic interstitial nephritis and uric acid urolithiasis. In the past, gout was referred to as the 'disease of the wealthy' due to its association with the quality of life. Epidemiological evidence suggests that gout affects $\sim 3.9 \%$ of adults and $12.6 \%$ of the elderly (aged $>80$ years) in the United States (1).

The pathogenesis of gout remains unclear. The fact that $<10 \%$ of patients with hyperuricosuria (2) develop gout indicates that genetic factors may contribute to the genesis and development of gout. A previous study (3) reported that the recognition of naked MSU crystals by specific toll-like receptors (TLRs), such as TLR2 (4), is a major factor in determining the inflammatory potential of MSU crystal deposits and the course of gouty arthritis. Polymorphisms of TLR2 deteriorate the function of proteins associated with certain diseases, for example, the TLR2 Arg753Gln polymorphism is associated with an increased risk of infective endocarditis (5), vitiligo (6) and atopic derma (7). Although the results of Hussein et al (8) indicated that the genotype and allele frequencies of $T L R 2 \mathrm{Arg} 753 \mathrm{Gln}$ were not associated with asthma or allergic rhinitis, a significant correlation with disease severity was observed. Brown et al (9) reported that this mutation may abrogate TLR2 signaling in response to human cytomegalovirus. Furthermore, the -174 to -196 del of TLR2 gene polymorphisms may confer an increased susceptibility to breast cancer development (10), gastric cancer (11) and prostate cancer (12). Therefore, the present study aimed to investigate the frequencies of TLR2 gene polymorphisms (Arg677Trp, Arg753Gln and the -196 to $-174 \mathrm{del}$ ) in patients with gout and explore the association between the polymorphisms and the susceptibility to gout in a Han Chinese population. 
Table I. Clinical characteristics of the GA and control groups (means $\pm \mathrm{SD}$ ).

\begin{tabular}{lccc}
\hline Characteristics & GA group $(\mathrm{n}=215)$ & Control group $(\mathrm{n}=216)$ & P-value \\
\hline Age, year & $54.59 \pm 13.23$ & $52.64 \pm 10.58$ & $0.091^{\mathrm{b}}$ \\
Gender, male, $\%$ & 93.49 & 92.59 & $0.715^{\mathrm{b}}$ \\
Median disease & 5 & - & - \\
duration, years & $577.70 \pm 106.64$ & $319.59 \pm 58.03$ & $<0.001^{\mathrm{a}}$ \\
UA, $\mu \mathrm{mol} / \mathrm{l}$ & $6.02 \pm 1.27$ & $5.57 \pm 1.34$ & $0.001^{\mathrm{a}}$ \\
GLU, $\mathrm{mmol} / \mathrm{l}$ & $2.14 \pm 1.41$ & $1.60 \pm 0.75$ & $0.000^{\mathrm{a}}$ \\
TG, $\mathrm{mmol} / \mathrm{l}$ & $5.05 \pm 1.08$ & $4.91 \pm 0.85$ & $0.150^{\mathrm{b}}$ \\
TC, $\mathrm{mmol} / \mathrm{l}$ & & & \\
\hline
\end{tabular}

Data were compared by the Student's t-test. ${ }^{\mathrm{a}} \mathrm{P}<0.05$ and ${ }^{\mathrm{b}} \mathrm{P}>0.05$ compared to the control group. GA, gouty arthritis; $\mathrm{SD}$, standard deviation; UA, serum uric acid; GLU, serum glucose; TC, total cholesterol; TC, triglycerides.

\section{Materials and methods}

Subjects. Unrelated patients $(\mathrm{n}=215)$ diagnosed with primary gouty arthritis (GA) were recruited from the Affiliated Hospital of North Sichuan Medical College (Nanchong, China) and the Affiliated Hospital of Medical College, Qingdao University (Qingdao, China) between January, 2008 and December, 2012. The clinical diagnosis of gout was established by the revised American College of Rheumatology classification criteria (13). The control group included 216 healthy subjects confirmed by medical examination at the Affiliated Hospital of North Sichuan Medical University during the corresponding period. All the subjects were of Han Chinese descent. The clinical data and measurements, including serum uric acid (UA), serum glucose (GLU), total cholesterol (TC) and triglycerides (TG), were assessed at the Department of Clinical Laboratory, the Affiliated Hospital of North Sichuan Medical University. The study was approved by the Ethics Committee and informed consent was obtained from all the participants.

Genomic DNA preparation. Whole blood samples (2 $\mathrm{ml})$ were collected from each subject by the standard venipuncture method (5). Genomic DNA was extracted from whole blood samples using the TIANamp Blood DNA kit (Tiangen Biotech, Co., Ltd., Beijing, China) following the manufacturer's instructions.

Analysis of the TLR2 polymorphisms. The single-nucleotide polymorphisms, Arg677Trp and Arg753Gln in TLR2 were genotyped by digestion with the restriction enzyme, AciI (Fermentas, Burlington, Canada), following polymerase chain reaction (PCR) amplification. The procedure was as follows: an initial denaturation step at $94^{\circ} \mathrm{C}$ for $5 \mathrm{~min}$, amplification was performed by 38 cycles at $94^{\circ} \mathrm{C}$ for $30 \mathrm{sec}, 58^{\circ} \mathrm{C}$ for $30 \mathrm{sec}$ and $72^{\circ} \mathrm{C}$ for $30 \mathrm{sec}$, followed by a final elongation cycle at $72^{\circ} \mathrm{C}$ for $5 \mathrm{~min}$ and then digested with AciI at $37^{\circ} \mathrm{C}$ for $15 \mathrm{~min}$. The products were electrophoresed on $3 \%$ agarose gel. Polymorphisms at TLR2-196 to -174 del were investigated using the PCR method following the procedures described by de Oliveira et al (11). Products were examined by electrophoresis in $1.5 \%$ agarose gel.
Statistical analysis. Statistical analyses were performed using SPSS software, version 16.0 (SPSS Inc., Chicago, IL, USA). A Student's t-test was performed to compare the clinical parameters between patients with gout and the healthy control subjects. Hardy-Weinberg equilibrium was assessed using the $\chi^{2}$ test for each TLR2 polymorphism. Significance of association was determined by $\chi^{2}$ or Fisher's exact test. The P-value, odds ratios (OR) and $95 \%$ confidence intervals (CI) were calculated. $\mathrm{P}<0.05$ was considered to indicate a statistically significant difference.

\section{Results}

Clinical parameters. A total of 431 subjects were enrolled in this study, including 215 patients with primary gout (200 men and 15 women) and 216 healthy controls (200 men and 16 women). The two groups were matched for age and gender. The UA levels of the GA group were significantly higher compared to that of the control group $(\mathrm{P}<0.05)$. Compared to the control group, the serum levels of GLU $(\mathrm{P}<0.05), \mathrm{TG}$ $(\mathrm{P}<0.05)$ and TC $(\mathrm{P}>0.05)$ were increased in the GA group (Table I).

In the GA group, 20\% of patients (43/215) exhibited high serum GLU levels (fasting glucose concentration was $>6.11 \mathrm{mmol} / \mathrm{l}$ ) and $>30 \%$ of patients had hyperlipemia (fasting plasma TG concentration was $>1.7 \mathrm{mmol} / \mathrm{l}$, TC level was $>5.72 \mathrm{mmol} / \mathrm{l}$ or both exceeded the normal value).

TLR2 gene polymorphisms. We genotyped three polymorphisms of the TLR2 gene, Arg677Trp, Arg753Gln and -196 to -174 del (Table II). The positive rate of polymorphisms in the samples was $96.52 \%$ (207/215 in the GA group and 209/216 in the control group). The AciI restriction enzyme identified the CCGC sequence, which existed in the wild-type sequence of Arg677Trp and Arg753Gln polymorphisms of $T L R 2$. When the wild-type of the two polymorphisms was digested by AciI, there were three bands of 38, 75 and $227 \mathrm{bp}$. Two bands (75 and 265 bp in Arg753Trp, 38 and 302 bp in Arg677Gln) were presented when the mutation of one polymorphism of TLR 2 had occurred. The amplified DNA of -196 to -174 del was 286 bp for the insertion allele and 264 bp for the deletion allele. 
Table II. Primer sequences, restriction enzymes and fragment sizes for the toll-like receptor 2 gene.

\begin{tabular}{|c|c|c|c|c|}
\hline $\begin{array}{l}\text { Gene } \\
\text { polymorphisms }\end{array}$ & Primers & $\begin{array}{l}\text { Enzyme } \\
{ }^{\circ} \mathrm{C} / \text { time }\end{array}$ & Fragment, bp & Refs. \\
\hline TLR2 R677W & F: 5'-GCCTACTGGGTGGAGAACCT-3' & AciI & Total: 341 & (14) \\
\hline TLR2 R753Q & R: 5'-GGCCACTCCAGGTAGGTCTT-3' & $37^{\circ} \mathrm{C}, 15 \mathrm{~min}$ & $\begin{array}{l}\text { Wild-type: } 38,75,227 \\
\text { R677W: } 75,265 \\
\text { R753Q: } 38,302\end{array}$ & \\
\hline $\begin{array}{l}-196 \text { to } \\
-174 \text { del }\end{array}$ & $\begin{array}{l}\text { F: 5'-CACGGAGGCAGCGAGAAA-3' } \\
\text { R: 5'-CTGGGCCGTGCAAAGAAG-3' }\end{array}$ & - & $\begin{array}{l}\text { ins/ins: } 286 \\
\text { ins/del: } 286,264 \\
\text { del/del: } 264\end{array}$ & $(11)$ \\
\hline
\end{tabular}

F, forward; R, reverse.

Table III. Genotype frequencies of toll-like receptor 2 gene polymorphisms in the GA and control groups.

\begin{tabular}{|c|c|c|c|c|c|c|}
\hline $\begin{array}{l}\text { Gene } \\
\text { polymorphisms }\end{array}$ & $\begin{array}{l}\text { Genotype } \\
\text { frequencies }\end{array}$ & $\begin{array}{l}\text { GA group, } \\
\mathrm{n}=215(\%)\end{array}$ & $\begin{array}{l}\text { Control group, } \\
n=216(\%)\end{array}$ & $\begin{array}{c}\text { Pearson } \\
\chi^{2}\end{array}$ & P-value & OR $(95 \% \mathrm{CI})$ \\
\hline \multicolumn{7}{|l|}{ TLR2 R677W } \\
\hline & $\mathrm{CC}$ & $207(96.28)$ & $209(96.76)$ & & & \\
\hline & $\mathrm{TC}$ & 0 & 0 & & & \\
\hline & $\mathrm{TT}$ & 0 & 0 & & & \\
\hline \multicolumn{7}{|l|}{ TLR2 R753Q } \\
\hline & GG & $207(100)$ & $209(100)$ & & & \\
\hline & $\mathrm{AG}$ & 0 & 0 & & & \\
\hline & AA & 0 & 0 & & & \\
\hline \multicolumn{7}{|l|}{-196 to } \\
\hline \multirow[t]{5}{*}{-174 del } & ins/ins & $27(13.04)$ & $24(11.48)$ & 1.686 & 0.430 & \\
\hline & ins/del & $96(46.38)$ & $87(41.63)$ & & & \\
\hline & $\mathrm{del} / \mathrm{del}$ & $84(40.58)$ & $98(46.89)$ & & & \\
\hline & ins & $150(36.23)$ & $135(32.30)$ & 1.430 & 0.232 & $1.191(0.894-1.587)$ \\
\hline & del & $264(63.77)$ & $283(67.70)$ & & & \\
\hline
\end{tabular}

GA, gouty arthritis; TLR2, toll-like receptor 2; OR, odds ratio; 95\% CI, confidence interval; ins, insertion; del, deletion.

The samples showed three bands of Arg677Trp and Arg753Gln polymorphisms, indicating that the GA and control groups were of the wild-type genotype. Our results suggested that there were no significant associations between the Arg677Trp and Arg753Gln polymorphisms of TLR2 with gout risk. However, different genotypes of the $T L R 2$ ins/del polymorphism were observed using the Hardy-Weinberg equilibrium. In the control group, the genotype frequencies were $11.48 \%$ for ins/ins, $41.63 \%$ for ins/del and $46.89 \%$ for $\mathrm{del} / \mathrm{del}\left(\chi^{2}=0.484, \mathrm{P}=0.487\right)$; the allele frequency was $32.30 \%$ for the ins allele and $67.70 \%$ for the del allele. In the GA group, the genotype frequencies were $13.04 \%$ for ins/ins, $46.38 \%$ for ins/del and $40.58 \%$ for del/del; the allele frequency was $36.23 \%$ for the ins allele and $63.77 \%$ for the del allele. There were no significant differences in genotype $\left(\chi^{2}=1.686, \mathrm{P}=0.430\right)$ and allele $\left(\chi^{2}=1.430, \mathrm{P}=0.232\right)$ frequencies of the -196 to -174 del polymorphism between the GA and the control groups. The del allele was not associated with the risk of gout $(\mathrm{OR}=1.191,95 \% \mathrm{CI}$ : 0.894-1.587). The genotype and allele frequencies of TLR gene polymorphisms in the control and GA groups are presented in Table III.

\section{Discussion}

Gout is a disorder caused by the precipitation or deposition of MSU in tissues and organs. The pathogenesis of gout has not yet been determined; however, $1-2 \%$ of primary gout is induced by the defect of purine metabolic enzyme. Studies have reported (15) that inflammation and immunity, particularly innate immunity, is associated with the generation and development of gout.

Genetic variants of innate immune receptors may be associated with the risk of disturbances. The polymorphisms of TLR2 may affect host defense, disease progression and are linked to certain disease susceptibilities. By contrast, the TLR2 +597CC genotype exhibited protective effects against colorectal cancer decreasing the risk by 5 -fold (16) in a Portuguese population. The TLR2 Arg753Gln gene 
polymorphism was associated with the increased levels of specific IgE in patients with allergic diseases (17). Thus, this mutation renders TLR2 signaling incompetent by impairing its tyrosine phosphorylation, dimerization with TLR6, and recruitment of the myeloid differentiation primary response gene 88 (MyD88) and MyD88-adapter-like proteins (18).

However, the correlation between gout and TLR 2 gene polymorphisms remains unclear. The present study investigated whether TLR2 polymorphisms (Arg753Gln, Arg677Trp and -196 to -174 del) affect the development of gout in a Han Chinese population. Gel electrophoresis results presented three bands in all the samples indicating no mutations of the TLR2 gene polymorphisms, Arg753Gln and Arg677Trp, in the GA and healthy control groups. Our results confirmed that the two polymorphisms of TLR2 did not exist in subjects who exhibited the wild-type allele for Arg753Gln and Arg677Trp. These results are consistent with previous studies in India $(19,20)$ and China $(21,22)$.

The -196 to -174 del polymorphism in the TLR2 gene causes a 22-bp nucleotide deletion, which alters the promoter activity of TLR2. The TLR2 del/del genotype was reported to decrease the transactivation of the promoters. In a North Indian population, the variant allele of $T L R 2$ (ins/del $+\mathrm{del} / \mathrm{del}$ ) was found to increase the risk of bladder cancer (23). Additionally, the -196 to $-174 \mathrm{del} / \mathrm{del}$ genotype of TLR2 may increase the risk of late-onset Alzheimer's disease (24). In contrast to the results of de Oliverira et al (11), Zeng et al (25) found that the variant allele of TLR2 (ins/del + del/del) significantly decreased the risk of gastric cancer in a Chinese population. By contrast, Hishida et al reported no association between the risk of gastric cancer and the TLR2 -196 to -174 del polymorphism in a Japanese population (26). Our findings indicate that there were no significant differences in genotype and allele frequencies of the -196 to -174 del polymorphism between the GA and control groups. The del allele was not associated with the risk of gout in the Han Chinese subjects.

This study has reported that the serum levels of UA, GLU, TG and TC were higher in the GA group compared to those in the healthy control group. The fasting glucose concentration in $20 \%$ of patients with gout was abnormal and $>30 \%$ of patients exhibited hyperlipemia. Results of the present study suggest that gout is a type of metabolic disease, which is accompanied by metabolic dysfunction. Diet control is required for patients with gout.

In conclusion, the TLR2 polymorphisms, Arg753Gln, Arg677Trp and -196 to -174 del, were not significantly associated with the risk of primary GA in a Han Chinese population. Accumulated data have indicated that TLR2 plays a pivotal role in the pathogenesis of gout $(27,28)$. TLR2 has a cytoplasmic Toll/interleukin(IL)-1 receptor (IL-1R) domain, which participated in the activation of downstream signaling pathways, including the activation of MyD88, interleukin-1 receptor-associated kinase, tumor necrosis factor receptor-associated factor, I $\mathrm{B}$ kinase and nuclear factor- $\kappa \mathrm{B}$, and ultimately induced the expression of proinflammatory messenger RNA (mRNA), such as the mRNA of IL-1 $\beta$, transforming growth factor (TGF) $\alpha$ and TGF $\beta 1$ (29). When chondrocytes are exposed to MSU crystals, this signaling pathway may be activated (30). Therefore, TLR2 not only recognizes naked MSU crystals, but also influences the release of inflammatory cytokines, such as IL-1 $\beta$, which is the core factor inducing the symptoms and signs of GA (31). Further studies focusing on other SNPs of TLR2 are required to determine whether there is an association between gout and TLR2 gene polymorphisms.

\section{Acknowledgements}

This study was supported by grants from the Key Laboratory Fund of North Sichuan Medical College [grant no. KFJJ (10)-10] and the National Science Foundation of China (grant no. 81272047). The authors would like to thank all the participants and their families as well as colleagues in the Department of Clinical Laboratory of the Affiliated Hospital of North Sichuan Medical University for the sample collection.

\section{References}

1. Crittenden DB and Pillinger MH: The year in gout: 2011-2012. Bull NYU Hosp Jt Dis 70: 145-151, 2012.

2. Richette P and Bardin T: Gout. Lancet 23: 318-328, 2010.

3. Liu-Bryan R, Scott P, Sydlaske A, Rose DM and Terkeltaub R: Innate immunity conferred by Toll-like receptors 2 and 4 and myeloid differentiation factor 88 expression is pivotal to monosodium urate monohydrate crystal-induced inflammation. Arthritis Rheum 52: 2936-2946, 2005.

4. Liu-Bryan R, Pritzker K, Firestein GS and Terkeltaub R: TLR2 signaling in chondrocytes drives calcium pyrophosphate dihydrate and monosodium urate crystal-induced nitric oxide generation. J Immunol 174: 5016-5023, 2005.

5. Bustamante J, Tamayo E, Flórez S,Telleria JJ, Bustamante E, López J, San Román JA, et al: Toll-like receptor 2 ARG753GLN polymorphisms are associated with an increased risk of infective endocarditis. Rev Esp Cardiol 64: 1056-1059, 2011.

6. Karaca N, Ozturk G, Gerceker BT, Turkmen M and Berdeli A: TLR2 and TLR4 gene polymorphisms in Turkish vitiligo patients. J Eur Acad Dermatol Venereol 27: 85-90, 2013.

7. Salpietro C, Rigoli L, Miraglia Del Giudice M, et al: TLR2 and TLR4 gene polymorphisms and atopic dermatitis in Italian children: a multicenter study. Int J Immunopathol Pharmacol 24: 33-40, 2011.

8. Hussein YM, Awad HA, Shalaby SM, Ali AS and Alzahrani SS: Toll-like receptor 2 and Toll-like receptor 4 polymorphisms and susceptibility to asthma and allergic rhinitis: a case-control analysis. Cell Immunol 274: 34-38, 2012.

9. Brown RA, Gralewski JH and Razonable RR: The ARG753GLN polymorphism abrogates toll-like receptor 2 signaling in response to human cytomegalovirus. Clin Infect Dis 49: 96-99, 2009.

10. Theodoropoulos GE, Saridakis V, Karantanos T, et al: Toll-like receptors gene polymorphisms may confer increased susceptibility to breast cancer development. Breast 21: 534-538, 2012.

11. de Oliveira JG and Silva AE: Polymorphisms of the TLR2 and TLR4 genes are associated with risk of gastric cancer in a Brazilian population. World J Gastroenterol 18: 1235-1242, 2012.

12. Mandal RK, George GP and Mittal RD: Association of Toll-like receptor (TLR) 2, 3 and 9 genes polymorphism with prostate cancer risk in North Indian population. Mol Biol Rep 39: 7263-7269, 2012

13. Wallace SL, Robinson H, Masi AT, Decker JL, McCarty DJ and Yü TF: Preliminary criteria for the classification of the acute arthritis of primary gout. Arthritis Rheum 20: 895-900, 1977.

14. Yoon HJ, Choi JY, Kim CO, et al: Lack of Toll-like receptor 4 and 2 polymorphisms in Korean patients with bacteremia. J Korean Med Sci 21: 979-982, 2006.

15. Punzi L, Scanu A, Ramonda R and Oliviero F: Gout as autoinflammatory disease: new mechanisms for more appropriated treatment targets. Autoimmun Rev 12: 66-71, 2012.

16. Pimentel-Nunes P, Teixeira AL, Pereira C, et al: Functional polymorphisms of Toll-likereceptors 2 and 4 alter the risk for colorectalcarcinoma in Europeans. Dig Liver Dis 45: 63-69, 2013.

17. Kutsenko NL, Izmă̌lova OV, Vesnina LÈ and Kaŭdashev IP: Relationship of toll-like receptors 2 and 4 genes polymorphisms with allergic diseases with increased levels of specific IgE. Tsitol Genet 46: 59-66, 2012 (In Russian). 
18. Xiong Y, Song C, Snyder GA, Sundberg EJ and Medvedev AE: ARG753GLN polymorphism inhibits Toll-like receptor (TLR) 2 tyrosine phosphorylation, dimerization with TLR6, and recruitment of myeloid differentiation primary response protein 88. J Biol Chem 287: 38327-38337, 2012.

19. Bali P, Pradhan S, Sharma D and Adak T: Toll like receptor 2 and 4 polymorphisms in malaria endemic populations of India. Hum Immunol 74: 223-229, 2013.

20. Myles A and Aggarwal A: Lack of association of single nucleotide polymorphisms in toll-like receptors 2 and 4 with enthesitis-related arthritis category of juvenile idiopathic arthritis in Indian population. Rheumatol Int 33: 417-421, 2013.

21. Chen L, Lin MJ, Zhan Ll and Lv XP: Analysis of TLR4 and TLR2 polymorphisms in inflammatory bowel disease in a Guangxi Zhuang population. World J Gastroenterol 18: 6856-6860, 2012.

22. Liu F, Lu W, Qian Q,Hu J and Feng B: Frequency of TLR 2, 4 , and 9 gene polymorphisms in Chinese population and their susceptibility to type 2 diabetes and coronary artery disease. J Biomed Biotechnol 2012: 373945, 2012.

23. Singh V, Srivastava N, Kapoor R and Mittal RD: Single-nucleotide polymorphisms in genes encoding toll-like receptor $-2,-3,-4$ and -9 in a case-control study with bladder cancer susceptibility in a North Indian population. Arch Med Res 44: 54-61, 2013.

24. Yu JT, Mou SM, Wang LZ, Mao CX and Tan L: Toll-like receptor 2-196 to -174 del polymorphism influences the susceptibility of Han Chinese people to Alzheimer's disease. J Neuroinflammation 11: 136, 2011.
25. Zeng HM, Pan KF, Zhang Y, et al: Genetic variants of toll-like receptor 2 and 5 , helicobacter pylori infection, and risk of gastric cancer and its precursors in a chinese population. Cancer Epidemiol Biomarkers Prev 20: 2594-2602, 2011.

26. Hishida A, Matsuo K, Goto Y, Naito M, Wakai K, Tajima K and Hamajima N: No associations of Toll-like receptor 2 (TLR2) -196 to $-174 \mathrm{del}$ polymorphism with the risk of Helicobacter pylori seropositivity, gastric atrophy, and gastric cancer in Japanese. Gastric Cancer 13: 251-257, 2010.

27. Lee YH, Bae SC, Kim JH and Song GG: Toll-like receptor polymorphisms and rheumatoid arthritis: a systematic review. Rheumatol Int: Jan 17, 2013 (Epub ahead of print).

28. Abu-Amero KK, Jaeger M, Plantinga T, Netea MG and Hassan HY: Genetic variation of TLR2 and TLR4 among the Saudi Arabian population: insight into the evolutionary dynamics of the Arabian Peninsula. Genet Test Mol Biomarkers 17: 166-169, 2013.

29. Takeda K, Kaisho T and Akira S: Toll-like receptors. Annu Rev Immunol 21: 335-376, 2003.

30. Kawai T and Akira S: The role of pattern-recognition receptors in innate immunity: update on Toll-like receptors. Nat Immunol 11: 373-384, 2010.

31. Mylona EE, Mouktaroudi M, Crisan TO, et al: Enhanced interleukin-1 $\beta$ production of PBMCs from patients with gout after stimulation with Toll-like receptor-2 ligands and urate crystals. Arthritis Res Ther 14: R158, 2012. 